\title{
A incomum trajetória de uma educadora popular
}

The uncommon path of a popular educator

La trayectoria poco común de una educadora popular

\author{
Paulo Rogério de Oliveira Teixeira \\ Universidade Católica de Santos (Brasil) \\ https://orcid.org/0000-0001-5623-6424 \\ http://lattes.cnpq.br/7728273656794403 \\ paulorogerio@unisantos.br \\ Luiz Carlos Barreira \\ Universidade Católica de Santos (Brasil) \\ https://orcid.org/0000-0002-6746-9706 \\ http://lattes.cnpq.br/0821428930913743 \\ luizcarlosbarreira@gmail.com
}

\section{Resumo}

O artigo discorre sobre a trajetória profissional de uma educadora popular que começou a se tornar professora quando ainda era adolescente, em uma fazenda de café, no estado do Paraná. Já adulta e residente em um bairro periférico da cidade de São Paulo, aproximou-se e passou a militar no Movimento dos Trabalhadores sem Terra - MST. Graças a essa sua militância, pôde graduar-se em Pedagogia (da Terra) e realizar uma especialização sobre o uso de sementes nativas e crioulas na agricultura. Não por acaso, advoga, hoje, uma educação do campo para o campo, ou seja, uma educação pensada e praticada por aqueles que, como ela, vivem em acampamentos e assentamentos de terra. A trajetória dessa educadora foi reconstruída por meio de entrevistas realizadas conforme procedimentos de pesquisa observados por historiadores que atuam no campo da História Oral. O mesmo ocorreu em relação à narração, que foi pensada, estruturada e produzida também de acordo com tais procedimentos, especialmente aqueles relacionados a uma técnica particular, denominada transcriação de entrevistas.

Palavras-chave: Educação popular. Movimento dos Trabalhadores Sem Terra - MST. Comuna da Terra Irmã Alberta. 


\begin{abstract}
This article discusses the professional life of a popular education teacher, who began teaching while still a teenager on a coffee farm in the state of Paraná, Brazil. As an adult living in a neighborhood on the outskirts of the city of São Paulo, she drew near the Landless Workers' Movement (Movimento dos Trabalhadores sem Terra - MST) and became active in it. Due to this activism, she was able to earn a degree in Ecopedagogy (Pedagogia da Terra), with specialization in the use of native and landrace seeds in agriculture. It is no coincidence that she now advocates education from the rural area for the rural area, that is, an education conceived and practiced by those who, like her, live in rural encampments and settlements. The life path of this educator was reconstructed through interviews conducted according to research procedures observed by historians active in the field of Oral History. Narration of this story was conducted in the same way; it was conceived, structured, and produced according to such procedures, especially those related to a particular technique called interview transcreation.
\end{abstract}

Keywords: Popular education. Movimento dos Trabalhadores Sem Terra - MST. Comuna da Terra Irmã Alberta.

\title{
Resumen
}

El artículo analiza la trayectoria profesional de una educadora popular, que comenzó a ser maestra cuando aún era una adolescente, que vivía y trabajaba en una finca cafetera en Paraná, uno de los estados de Brasil. Esta trayectoria continuó cuando se mudó, más tarde, a São Paulo, que es otro estado de Brasil. Allí, viviendo en un barrio periférico de la ciudad, conoció y comenzó a trabajar en el Movimiento de Trabajadores Rurales Sin Tierra - MST. Gracias a su activismo logró graduarse en Pedagogía (desde la Tierra) y especializarse en el uso de semillas nativas y criollas en la agricultura. No es por casualidad que ahora aboga por la educación del campo al campo, es decir, una educación pensada y practicada por quienes, como ella, viven en campamentos y asentamientos. La trayectoria de este educador se reconstruyó a través de entrevistas, realizadas a partir de procedimientos de investigación observados por historiadores que trabajan con Historia Oral. Lo mismo ocurrió en relación con la narración, que fue pensada, estructurada y producida también de acuerdo con dichos procedimientos, principalmente los relacionados con una determinada técnica, llamada transcreación de entrevistas.

Palabras clave: Educación popular. Movimiento de Trabajadores Sin Tierra - MST. Comuna de Terra Irmã Alberta. 
a memória não depende de competências mais ou menos científicas para funcionar, pois, fugidia e orgânica, apresenta-se em grupos que sentem ou ressentem o mundo; a capacidade de sentir o mundo é possibilitada por um encontro da "memória sentida" com a "memória do sentido" sempre construído por circunstâncias.

José Carlos Sebe Bom Meihy \& Leandro Seawright

Este artigo narra a trajetória de vida e profissional de uma mulher nordestina que, ainda criança, migrou com a família para o estado de São Paulo, onde iniciou sua vida escolar. Poucos anos depois, em outro movimento de migração, a família transferiu-se para o estado do Paraná. Lá, a criança trabalhou em fazendas de café e deu continuidade à sua educação escolar. Uma educação que deixou marcas profundas, sobretudo por ser regida pelo tempo do campo, das plantações de café. Foi nesse ambiente rural, ainda adolescente, que sua trajetória como educadora teve início. Primeiramente, e por força do acaso, como professora primária leiga. E, alguns anos mais tarde, como educadora voluntária de jovens e adultos, desta vez, por opção política.

De retorno a São Paulo, tornou-se militante em movimentos sociais organizados. Entre outras atividades, trabalhou em projetos de educação, desenvolvidos no âmbito do Movimento de Alfabetização de Jovens e Adultos - MOVA ${ }^{1}$. Em uma rádio clandestina, na comunidade onde morava, trabalhou como locutora. Foi nessa rádio que conheceu e entrevistou duas lideranças do Movimento dos Trabalhadores Sem Terra, MST, que atuavam na Vila Brasilândia, bairro periférico da cidade de São Paulo. Esse encontro representou um marco na vida dessa mulher, pois foi a partir dele que sua vida deu uma guinada de cento e oitenta graus, como se diz. Abandonou a vida que levava e começou a se dedicar em tempo integral ao MST. A partir daquele momento, sua vida como educadora popular também passou por profundas transformações, como se verá mais adiante. $\mathrm{O}$ que jamais imaginara viver, começou a se fazer realidade.

Essa mulher, cuja história de vida e trajetória profissional será aqui narrada, chamase Mari Alves e é uma das acampadas no acampamento Comuna da Terra "Irmã Alberta", erguido em terreno ocupado pelo MST há quase vinte anos. Ela e outros acampados nessa mesma Comuna foram entrevistados por Paulo Rogério de Oliveira Teixeira em sua pesquisa de dissertação de mestrado (TEIXEIRA, 2019). Nesse seu trabalho de pesquisa, Teixeira reuniu todas as entrevistas que realizou em um banco de histórias.

\footnotetext{
${ }^{1}$ O Mova surgiu em 1989 durante a gestão de Paulo Freire na Secretaria Municipal de Educação de São Paulo, com uma proposta que reunia organizações do estado de São Paulo e organizações da sociedade civil para combater o analfabetismo entre jovens e adultos. Disponível em: http://www.educabrasil.com.br/mova/. Acesso em: 15 mar. 2018. Em 2005, um Projeto de Lei (Lei No 14.05, de 10 de outubro de 2005), com base no Projeto de Lei $\mathrm{n}^{\circ}$ 110/05, do Vereador Paulo Fiorilo, do Partido dos Trabalhadores, institui novamente o MOVA no município de São Paulo, em uma votação realizada na Câmara Municipal de São Paulo, no dia 14 de setembro desse mesmo ano, e promulgada pelo então Prefeito, José Serra.
} 
Figura 1 - Entrada do acampamento

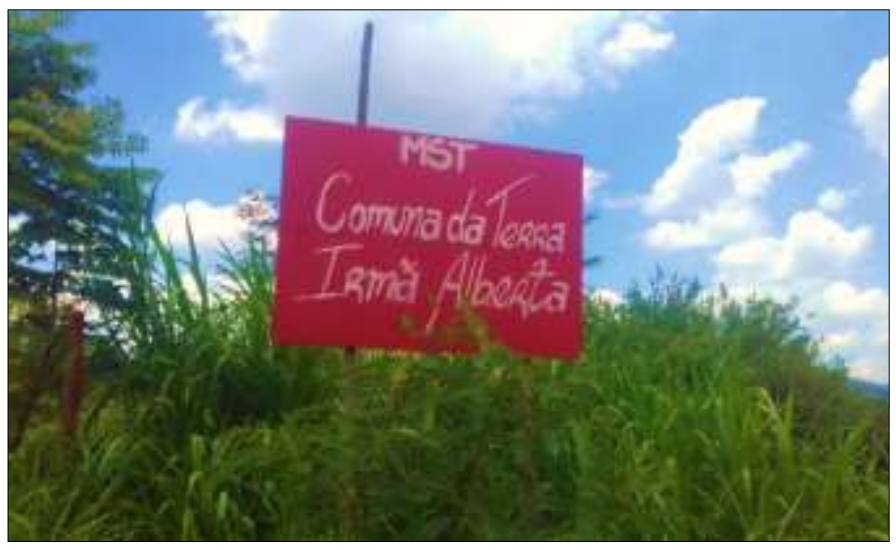

Fonte: Teixeira (2019)

Tanto nas entrevistas transcritas de Mari Alves, que se encontram preservadas nesse banco de histórias, como nos registros de campo feitos por Teixeira (2019), algo chama a atenção: a incomum trajetória profissional de Mari no campo da educação popular. Optou-se, então, por elaborar um projeto de pesquisa, cujo principal objetivo seria o de reconstruir, significando, a trajetória profissional de Mari Alves, operando, assim, um esforço coletivo de organização da memória de expressão oral dessa educadora popular.

Para tanto, recorreu-se a procedimentos de transcriação, cuja principal fonte de inspiração está nos estudos e trabalhos de pesquisa realizados por José Carlos Sebe Bom Meihy no Núcleo de Estudos em História Oral da Universidade de São Paulo (MEIHY, 1991; 2006), especialmente em seu último trabalho, recentemente publicado em coautoria com Leandro Seawright (MEIHY; SEAWRIGHT, 2020). Nesse último trabalho, encontra-se a seguinte reflexão:

Transcriação é um gesto diante da existência e não somente uma oportuna operação em história oral. Como operação, contudo, serve para o tratamento de entrevistas e [...] pode servir para o entendimento do que é análise; por suposto, se a memória antecede à história oral, a transcriação acompanha os níveis de verbalização da memória em diferentes estados de expressão: antes da gravação, durante a gravação e, depois, quando do referido tratamento de entrevistas. Convém esclarecer que parte do potencial explicativo das entrevistas é resolvido na transcriação como procedimento de tratamento de entrevistas. (MEIHY; SEAWRIGHT, 2020, p. 160; grifos no original).

No exercício de transcriação das entrevistas concedidas por Mari Alves, foram também consideradas, como alternativas de análise, as percepções gerais, sensações e observações de Teixeira (2019) sobre os contatos presenciais que ele teve com os sujeitos da pesquisa, por ele registradas em seu caderno de campo. Tais contatos foram vários e não se limitaram aos momentos das entrevistas, propriamente ditas. Teixeira permaneceu no acampamento por alguns dias, retornando a ele poucos meses depois; participou de atividades, dentro e fora do acampamento, promovidas pelos acampados, com os quais estabeleceu relações de solidariedade e amizade. Assume-se, portanto, ainda na esteira de Meihy e Seawright (2020, p. 161): 
que transcriação em história oral é recriação não da linguagem ou do poema, mas, valendo-se da tradução poética, constitui-se como operação de memória verbal e de história oral, na análise também se pode fazer algo novo [...] no interior do texto: "transmemoriar", unindo ou não as pontas das lembranças, a partir do entendimento da memória coletiva. Ora, que a expressão oral da memória falhe, erre, minta, distorça, corrompa e opere em devaneios, sonhos, inconsistências, lapsos, elucubrações, profecias fantásticas, visões, utopias, distopias, ucronias, crenças, descrenças, ideologias é algo não apenas "tolerável”, mas pretendido para se dimensionar o caráter subjetivo tão descartado por posições científicas quase sempre transplantadas.

$\mathrm{Na}$ análise dos registros de fala (entrevistas transcritas) e dos registros de campo:

não é incomum que o oralista faça remessas à sua própria área de conhecimento formal ou de formação: conhecem-se, assim, os historiadores, os psicólogos, os sociólogos, os pedagogos, entre outros profissionais, por meio de suas abordagens que refluem aos respectivos campos. (MEIHY; SEAWRIGHT, 2020, p. 160).

Assim, o "lugar de fala" dos autores da presente transcriação analítica poderá ser facilmente identificado na materialidade deste artigo. Esse "lugar de fala" não revela apenas o campo disciplinar em que se formaram e no qual atuam, mas também, e principalmente, a visão do mundo e da história, bem como o campo político e ideológico de atuação de cada um deles.

Como se verá, a história de vida e o percurso profissional de Mari Alves é síntese de muitas determinações, dentre as quais destacamos as seguintes: o desejo de ensinar, cultivado desde muito cedo e realizado por força de circunstâncias casuais; comportamento de liderança, fortemente arraigado em uma consciência de classe forjada na luta pela sobrevivência; a presença ativa de movimentos sociais organizados, como o MOVA e o MST, no processo de formação política das classes trabalhadoras; a iniciativa de instituições de ensino superior, como UFSCar e USP, oferecendo cursos de formação política a trabalhadores organizados em sindicatos e movimentos sociais, como CUT e MST. Em poucas palavras, Mari Alves tornou-se uma educadora popular no seio de uma sociedade civil muito retraída e gelatinosa, pois recém-saída de um regime político de exceção, que exacerbou o poder do Estado e submeteu a sociedade civil aos seus interesses e aos das classes economicamente dominantes, e que perdurou por mais de vinte anos.

A narrativa sobre a trajetória de Mari Alves, na educação popular, contempla diferentes momentos históricos da vida dessa educadora, que vão do seu nascimento aos dias de hoje. Atribuiu-se um título a cada um desses momentos, com o objetivo de, por meio deles, explicitar, de forma sintética, os sentidos que a protagonista da história aqui narrada atribui a cada um deles no presente. ${ }^{2}$

\footnotetext{
${ }^{2}$ É preciso esclarecer que, mesmo Teixeira (2019) tendo observado todos os protocolos definidos pela História Oral, especialmente no que diz respeito à carta de cessão dos direitos autorais das entrevistas que lhe foram concedidas, os autores deste artigo também procederam de acordo com tais protocolos, ou seja, receberam o aval, a carta de cessão plena dos direitos autorais de Mari Alves para a divulgação dos resultados finais do processo de "transcriação analítica" das entrevistas anteriormente concedidas por ela.
} 


\section{Filha de retirantes}

Meu nome é Maria Alves Silva, mais conhecida por Mari Alves. Minha militância em movimentos sociais organizados e comprometidos com os interesses das classes trabalhadoras teve início quando eu conheci o Movimento dos Trabalhadores Sem Terra, o MST, em minha peregrinação pelo campo da educação popular. Sou uma acampada e sonho com o assentamento dos trabalhadores que, em 20 de julho de 2002 - há dezoito anos, portanto -, liderados pelo MST, ocuparam um terreno localizado no bairro de Perus, na cidade de São Paulo, onde ergueram um acampamento chamado Comuna da Terra Irmã Alberta. Desde então, vivo nesse acampamento e sou uma das responsáveis por sua gestão. Minha vida de educadora, entretanto, começou muito antes desse meu encontro com o MST. É uma longa história, que começa quando eu ainda era uma adolescente, até mesmo antes disso.

Nasci em julho de 1953, em uma pequena cidade do sertão paraibano, chamada Princesa Isabel, que fica na divisa com o estado de Pernambuco. Filha de retirantes, meus pais chegaram ao interior do estado de São Paulo quando eu ainda era uma criança. Trabalhavam na roça. Alguns anos depois, eles foram para o estado do Paraná, e lá trabalharam em lavouras de café. Como todo filho de trabalhador rural, levantava-me bem cedo para ajudar meu pai na lida. Foi assim que aprendi a trabalhar a terra.

\section{Aluna e professora leiga em escolas rurais}

Na roça, nem sempre era possível frequentar escolas, isto é, quando elas existiam. As poucas escolas em que estudei ficavam à beira das estradas e o acesso a elas era difícil. Às vezes, era preciso caminhar cerca de cinco, seis quilômetros ou cavalgar por léguas para chegar à escola. Como as relações de trabalho no campo eram muito precárias, tínhamos que mudar frequentemente de fazenda e isso produzia efeitos desastrosos na minha vida escolar, bem como na vida dos professores e do próprio ensino rural. Mas essa instabilidade do corpo discente não era o único fator a fazer do ensino rural um ensino precário e fragmentado.

As escolas rurais que frequentei, lá no Paraná, funcionavam apenas seis meses no ano. Além de não haver interesse dos governos municipais locais em manter escolas rurais funcionando o ano inteiro, nem mesmo em garantir um professor permanente em cada uma delas, os filhos dos trabalhadores rurais só podiam frequentar a escola nas entressafras, pois sua mão de obra era considerada indispensável à colheita. Quando a escola voltava a funcionar, eles retornavam às aulas, mas a prolongada interrupção nos estudos, associada à ausência de professores permanentes, tornavam o aprendizado bastante precário. Por isso, a grande maioria continuava analfabeta ou semialfabetizada aos quinze anos de idade. Tive sorte, pois quando chegamos ao Paraná, eu já estava no terceiro ano do curso primário e havia uma professora permanente na fazenda onde fomos trabalhar. Essa professora, cujo nome não me lembro, morava na cidade, mas ia à fazenda no início da semana e lá permanecia durante toda a semana. O proprietário da fazenda era um cidadão influente na região, e em suas fazendas não poderiam faltar professores permanentes. A história evidenciou, entretanto, que ser politicamente influente não era condição necessária e suficiente para a manutenção da dedicada professora permanente na escola dessa fazenda. Não sei por qual razão a professora deixou a escola, que passou a funcionar como as demais, ou seja, a cada seis meses, nas entressafras da cultura do café. Permaneceu, porém, a lembrança de uma profissional dedicada e comprometida com o seu trabalho, bem como o exemplo marcante do compromisso da comunidade com a escola. Tudo que ali vivi, naqueles anos, levo comigo ainda hoje. Por isso considero fundamentais os primeiros anos 
escolares no processo de formação do ser social. Nas longas interrupções das atividades escolares, eu estudava por conta própria, pois já havia adquirido o hábito.

O cultivo da leitura, por exemplo, foi incentivado por meus pais. Quando os próprios pais incentivam, as crianças ficam bastante motivadas. Minha mãe, por exemplo, que era analfabeta, pedia-me para que eu lesse para ela os livros de contos de fada que me eram emprestados pela professora da escola rural da fazenda onde trabalhávamos, em São Paulo, recém-chegados do Nordeste. No Paraná, sobretudo depois de a escola rural que eu frequentava ter perdido sua professora permanente e a escola passar a funcionar a cada seis meses, o cenário, em casa, estimulava o cultivo da leitura. Semanalmente, meu pai trazia para casa jornais e livros de cordel. Ele, que era semialfabetizado, gostava que eu lesse para ele aqueles "livrinhos de cordel", cujas histórias ele tanto amava, talvez porque fizessem com que ele se lembrasse da sua cultura, da sua terra natal. Os jornais eram dobrados e separados para serem lidos por mim ao longo da semana. Eram leituras importantes, pois o acesso a livros era praticamente impossível, nas condições em que nos encontrávamos.

Passados alguns anos, a situação da escola rural, lá no Paraná, particularmente na região onde estávamos, havia piorado ainda mais. Às precárias condições de trabalho do professor, somavam-se as não menos precárias condições dos espaços físicos onde as escolas funcionavam. Na fazenda onde trabalhávamos, por exemplo, havia uma escola de madeira, que desabou. Essa escola foi reerguida pelos trabalhadores, mas não havia professor designado para ela. A comunidade recorreu ao Prefeito, na tentativa de resolver o problema. Foi nesse contexto que comecei a me fazer professora.

Reerguida a escola de madeira, a comunidade foi ao Prefeito para que ele me contratasse como professora da escola. Dadas as dificuldades, então enfrentadas, para se encontrar e contratar professores dispostos a trabalhar na zona rural, o Prefeito concordou em me contratar. Mas, para eu poder assumir as aulas, eu teria que me submeter a um exame de equivalência ao quinto ano primário. Fiz o tal exame e fui aprovada. Satisfeita a condição, pude começar a trabalhar, mesmo não tendo formação profissional para o exercício da função. Por dois anos consecutivos fui a alfabetizadora das crianças daquela comunidade de trabalhadores rurais.

A escola ficava distante de onde morávamos. Os alunos eram muitos - acho que mais de quarenta, não me lembro ao certo. Crianças que, na sua maioria, nunca haviam frequentado uma escola. Embora o salário fosse mínimo, trabalhava com amor e satisfação. Aquele trabalho foi uma das minhas primeiras realizações. Vez ou outra, fico sabendo de comentários feitos por aqueles meus primeiros alunos. São muito gratos a mim por ter-lhes dado a oportunidade de aprender a ler, escrever e contar. Muitos deles deram continuidade aos estudos e isso me deixa muito feliz e realizada.

\section{Educadora e militante em movimentos sociais}

Em meados da década de 1970, ao retornar ao estado de São Paulo, precisamente à cidade de São Paulo, trabalhei em vários ramos da economia, que não guardavam qualquer relação com a educação. Por não ser formada no magistério, não podia lecionar. $\mathrm{O}$ fato de eu estar morando em uma comunidade carente possibilitou, entretanto, o meu retorno ao campo da educação. A comunidade ficava ao pé da Serra da Cantareira e não contava com lideranças dispostas a assumir a responsabilidade da condução da luta política da comunidade e do encaminhamento de suas reivindicações. Foi então que eu comecei a atuar junto à comunidade, tornando-me uma de suas lideranças. Por conta dessa minha atuação, fui convidada a participar de práticas de educação popular.

Dentre os vários cursos de formação de quadros para a educação popular que comecei a frequentar, assim que retornei a São Paulo, destacaria aqueles que foram oferecidos pela 
Pontifícia Universidade Católica de São Paulo - PUCSP, Associação de Estudantes Católicos - AEC, Centro Cida Romano e Centro Cultural Vereda, entre outras instituições. Assim, quase que "naturalmente", cheguei à Ação Educativa e, por meio dela, comecei a participar do Movimento de Alfabetização de Jovens e Adultos - MOVA.

Foi nesse contexto que eu comecei a atuar no campo da educação popular. Não trabalhava mais na indústria, pois eu fora dela afastada por problemas de saúde. Participei do projeto Arte na Rua, que trabalhava com crianças carentes. Envolvi-me com movimentos de saúde popular, nas Unidades Básicas de Saúde. Atuei como educadora de jovens e adultos - EJA, por cinco anos. Essa foi uma ótima experiência, pois eu abordava temas que diziam respeito à educação ambiental, bastante pertinentes, portanto, ao cotidiano do trabalho no campo.

Paralelamente a isso tudo, eu também trabalhava em uma rádio comunitária chamada Rádio Cantareira, na comunidade onde eu morava, no bairro de Vila Brasilândia. Esse projeto de rádio começou a funcionar sob minha responsabilidade, mesmo sem regulamentação. O transmissor ficava em um local bastante protegido. Chegávamos a esse local e lá permanecíamos trancados. Ligávamos o transmissor e começávamos a trabalhar, sempre atentos às possíveis ameaças. Quando percebíamos alguma delas, interrompíamos rapidamente a transmissão, saíamos do local, que permanecia trancado "a sete chaves". Trabalhamos nesse clima por muito tempo. Cheguei até a fazer um curso de técnica de locução, o que me permitiu comandar um programa aos sábados. Certo dia, o idealizador e proprietário dessa rádio pediu-me para entrevistar dois dirigentes do MST, que estavam na comunidade realizando um trabalho de panfletagem. Jamais esquecerei tal pedido. Graças àquela entrevista eu pude conhecer melhor o trabalho do MST. Fui convidada, por esses dois dirigentes, a participar de um encontro de coordenadores e monitores do MST, que eles promoveriam dali a alguns dias em uma igreja que ficava próxima à comunidade. Compareci a esse encontro e, desde então, passei a integrar o movimento. Para isso, entretanto, tive que interromper o trabalho que há cinco anos vinha realizando como educadora de jovens e adultos na comunidade onde eu morava.

Lembro-me muito bem do dia em que dei ciência aos meus alunos da minha decisão. Logo após o encontro com os dirigentes do MST e minha decisão de filiar-me e dedicar-me a ele, entrei em sala de aula com alguns panfletos, expliquei aos alunos o que era o MST, disse-lhes que eu estava aderindo a ele e que, por isso, estava deixando a comunidade e, consequentemente, o trabalho que eu estava nela realizando, inclusive com eles. Todos ficaram pasmos com minha decisão e perguntaram-me o que aconteceria com eles. Pedi a eles que se acalmassem, que eles não seriam abandonados e que eu continuaria com eles até a chegada de um novo professor. Aqueles dias foram muito difíceis para mim, pois eu trocava o certo pelo incerto.

Tenho muitas lembranças desse período. Na comunidade em que eu havia vivido até então, na Vila Brasilândia, eu ajudava a desenvolver projetos, como os idealizados pelo MEB, Movimento de Educação de Base, e financiados pela CNBB, Confederação Nacional dos Bispos do Brasil, e recebia uma pequena remuneração por esse trabalho. Não era muito, mas era certo e dava para viver. No MST, o trabalho seria apenas voluntário, portanto, não remunerado. Era trabalho de militante, de alguém que acreditava na causa perseguida pelo movimento. Por essa razão, alguns dos meus companheiros da Vila não acreditaram, inicialmente, que eu sairia de lá, que eu abandonaria o certo pelo duvidoso. Mas foi o que eu fiz.

Minha vida de educadora popular, entretanto, continuou. Quando, no acampamento do MST que me havia sido designado para começar a viver e a lutar, ficaram sabendo que eu trabalhava como educadora popular no MOVA há mais de cinco anos, propuseram-me montar e assumir uma sala de EJA no local. E assim foi. Rapidamente eles ergueram um barraco de lona nos fundos do acampamento onde hoje se encontra localizado o 
assentamento Dom Pedro Casaldàliga. No dia seguinte eu já estava lá com os companheiros, fazendo aquilo que eu mais gostava: ensinar.

Nesse acampamento do MST, as aulas encerravam-se às $18 \mathrm{~h} 30$. Então, eu pegava um ônibus que passava na estrada próxima ao acampamento, descia na comunidade onde eu havia morado até então, e ia direto para a sala de EJA. Fiquei nessa rotina por um tempo, o tempo necessário para os dirigentes do MOVA prepararem outro educador para ficar em meu lugar. E foi o que aconteceu. A partir de então, comecei a viver com dedicação exclusiva ao MST.

$\mathrm{Na}$ condição de acampada e supervisora de acampamento, fui designada, pela direção do MST, para ir ao Rio Grande do Sul e fazer um curso técnico de nível médio sobre educação de jovens e adultos, que era oferecido pelo Instituto Técnico de Estudos e Pesquisas da Reforma Agrária - ITERRA, na Escola Josué de Castro. Mesmo com toda a formação que eu havia adquirido ao longo da minha militância em movimentos de educação popular, os dois anos que eu passei nessa escola gaúcha foram de grande aprendizado, foram simplesmente fantásticos. Quando retornei ao acampamento, estava determinada a aplicar todo conhecimento que eu havia adquirido no curso. Queria fazer meu roçadinho de milho, formar uma horta, ou seja, fazer com que o meu lote, no acampamento, passasse a ser produtivo. Em meio a esse entusiasmo, fui informada que eu havia sido indicada para integrar a primeira turma do curso de Pedagogia da Terra, que começaria a ser oferecido, naquele ano, pela Universidade Federal de São Carlos UFSCar. E lá fui eu novamente para a sala de aula.

\section{"Foi um desafio e tanto, para mim, fazer um curso de nível superior"}

Esse curso de Pedagogia da Terra teria quatro anos de duração, como os demais cursos de Pedagogia. Começaria em 2008 e terminaria em 2011. A primeira turma, a qual integrei, começou com sessenta alunos e teve pouquíssimas desistências ao longo dos quatro anos. Todos os alunos eram trabalhadores vinculados a movimentos sociais rurais que haviam firmado parceria com a UFSCar para a formação de seus quadros, como o MST, a Federação dos Empregados Rurais e Assalariados do Estado de São Paulo FERAESP, a Organização de Mulheres Assentadas e Quilombolas do Estado de São Paulo - OMAQUESP, a Federação (dos trabalhadores) da Agricultura Familiar (do Estado de São Paulo) - FAF, além de quilombolas.

Cursar uma faculdade foi um desafio e tanto para mim, mas eu consegui ultrapassar todos os obstáculos. Concluí, obtendo nota máxima (dez) no meu Trabalho de Conclusão de Curso. Devo essa oportunidade de realização pessoal e profissional ao MST e à UFSCar.

Dada a minha vivência e experiência com educação popular, o tema do meu trabalho de conclusão do curso foi sobre uma prática bastante recorrente, principalmente nos acampamentos do MST: as Cirandas.

A Ciranda é uma escola diferente, não é um “depósito de crianças”, como muitas creches que eu conheço. Antes de tudo, a criança precisa gostar de estar lá, naquele lugar, durante todo o tempo em que lá permanecer. Por isso, a Ciranda precisa saber despertar o interesse da criança, mas sem deixar de ser propositiva e diretiva. É um espaço de brincadeiras, arte e diversão, mas também de muito aprendizado. É um espaço de formação. Há uma pedagogia a nortear as práticas dos educadores que realizam, nesse espaço, parte do trabalho de todo o processo de formação de uma criança, tenham esses educadores formação específica ou não.

A formação dos educadores que atuam ou atuarão nas Cirandas é de fundamental importância. A maioria desses educadores aprende e forma-se na prática. Uma das principais características das Cirandas está no fato de os seus educadores integrarem o acampamento e estarem vinculados ao MST. 
Os educadores que atuam nas Cirandas têm que aprender toda a dinâmica de trabalho com crianças. As mães, sempre que possível, também participam desse espaço de convivência. O sentimento de comunidade vai se fortalecendo aos poucos na criança. Suas mães estão com elas. Seus professores (educadores) também fazem parte da comunidade. Todos estão ali, em torno da criança. A comunidade faz-se presente o tempo todo. Isso faz com que as crianças acampadas se sintam em casa, na companhia dos seus. Vínculos de identidade começam a surgir e a se fortalecer.

O sentimento de solidariedade, assim como o de identidade, também é cultivado nas Cirandas. Tal sentimento é preocupação constante dos educadores e é cultivado, por exemplo, nos horários de merenda. As mães já sabem como proceder, pois, preocupamo-nos muito com a boa alimentação das crianças. Tudo é de todos e é repartido independentemente de quem o fez. Todas as vezes que o acampamento recebe alguma doação de alimento, de bolachas, por exemplo, esse alimento é de todos e todos cuidarão dele. Não existe a possibilidade desse alimento ou de qualquer outro tipo de doação ser apenas de um ou de alguns.

A Ciranda é muito importante para o acampamento. Ainda que a criança frequente outra escola, ela continua a participar das atividades promovidas pela Ciranda ao retornar ao acampamento, pois entendemos ser esse o espaço que fará com que a criança se mantenha ligada às lutas do acampamento.

A luta por terra e educação, aqui no acampamento Comuna da Terra Irmã Alberta, foi o tema que desenvolvi no meu trabalho de conclusão de curso em Pedagogia da Terra, na UFSCar (Cf. SILVA, 2011). Nele, descrevo essa luta. Falo da educação infantil dentro de um acampamento do MST, da luta pela alfabetização de jovens e adultos, do meu compromisso com a educação. Explicito a compreensão que fui adquirindo acerca da atuação do MST. Tratase de uma atuação pedagógica, de um "movimento pedagógico", pois, a partir do momento em que o sujeito começa a participar do Movimento, ele pode se desenvolver, crescer, no sentido de melhorar suas condições de vida e de estudo, como também pode proporcionar isso aos outros. É como um ciclo: o sujeito sai daquela vida miserável em que se encontra, tem sua autoestima elevada, porque planta, produz seu alimento, participa de projetos coordenados pelo Movimento e, assim agindo, cresce e faz crescer o Movimento.

Fazer o curso de Pedagogia da Terra e escrever esse trabalho não foi nada fácil para mim. Além das minhas limitações físicas, pois tenho problemas de artrose, meu desfio maior foi ter que ler e compreender os textos que compunham a bibliografia das disciplinas que integravam a matriz curricular do curso, um mais difícil que o outro. Para quem não sabia o que era ambiente acadêmico, que nunca havia estudado em escolas "de ponta", mas apenas frequentado escolas rurais, cujas condições de ensino eram bastante precárias, a única saída era quebrar paradigmas, ou seja, ser muito mais disciplinado do que os demais e realizar um esforço sobre-humano de compreensão daqueles textos, das discussões que fazíamos em sala de aula e, ainda, de aprender a escrever de forma clara, concisa e coerente, além de gramaticalmente correta. É claro que todo esse aprendizado não acontece da noite para o dia. Pode levar anos! O mais importante, entretanto, é que as sementes foram lançadas em terreno fértil e que muitas delas poderão germinar, se forem bem cuidadas. Para que isso ocorra, entretanto, é preciso poder contar com pessoas que estendam suas mãos aos necessitados. Foi o que aconteceu comigo.

Em meu último ano de permanência na universidade, quando eu escrevia o meu trabalho de conclusão de curso, encontrei-me, certa feita, com o orientador do trabalho, professor Dr. Luiz Bezerra Neto. Disse a ele, naquele momento, que eu gostaria de fazer um trabalho de qualidade, um trabalho que correspondesse às expectativas acadêmicas. $\mathrm{O}$ fato de eu ser uma mulher da roça não poderia ser tomado como desculpa, como uma autorização velada para eu poder fazer um trabalho qualquer. Não, em hipótese alguma. Pedi ajuda a ele e fui prontamente atendida. Recebi toda orientação necessária para a 
realização desse meu trabalho acadêmico. Como consequência, fui aprovada com nota máxima pelos doutos membros da banca que avaliaram o meu trabalho. Um sentimento de júbilo tomou conta de mim naquele momento. Somente gente como eu seria capaz, não de compreender, mas de mensurar e avaliar tal sentimento.

\section{"Arrastando malas novamente"}

Cumprida a missão, deixei de lado os livros, computador e outros materiais que havia trazido de São Carlos, desejando ardentemente cuidar da minha roça. Mas não me deram tempo para isso. Meu desempenho no curso de Pedagogia da Terra fez com que os dirigentes do MST me dessem outra missão universitária, desta vez na Faculdade de Educação da Universidade de São Paulo. Tratava-se de um curso de especialização em residência agrária, algo pelo qual eu já vinha lutando há muito tempo. Não pensei duas vezes para aceitar o convite. Voltei, assim, à vida acadêmica. Voltei a arrastar malas, a viver de um lado para outro, mas muito feliz.

Esse curso de especialização foi oferecido em parceria com a Escola Nacional Florestan Fernandes. $\mathrm{O}$ alojamento dos alunos ficava nessa escola. $\mathrm{O}$ ambiente era tranquilo, pois esse espaço era nosso. Na USP, entretanto, tivemos que marcar nosso espaço, como sempre acontece com pessoas que vêm de regiões socialmente marginalizadas. Mas foi muito bom, pois reencontrei pessoas maravilhosas, como a professora Dra. Lisete Regina Gomes Arelaro, que eu já conhecia dos movimentos de educação popular, quando eu ainda nem imaginava que um dia iria trabalhar com esse tema.

Foi um curso maravilhoso! Graças a ele, pude retomar e aprofundar temas e questões que foram abordados de forma superficial na minha graduação, particularmente no meu trabalho de conclusão de curso. Temas e questões que eu tinha muita vontade de retomar e que foram viabilizadas nesse curso. Aproveitei a oportunidade e desenvolvi um trabalho sobre uso e conservação de sementes nativas e crioulas no acampamento Comuna da Terra Irmã Alberta. Fiz um trabalho primoroso (Cf. SILVA, 2015).

A professora que orientou esse meu trabalho de conclusão de curso era uma mulher bastante engajada, viajada e conhecedora do tema. Aonde ela ia, levava consigo uma sacola de sementes crioulas. Isso nos ajudou muito, pois pudemos realizar experimentos com essas sementes. Aliás, o objetivo perseguido por essa professora era o de disseminar o uso de sementes nativas e crioulas, especialmente no universo daqueles que lutavam pela posse da terra, como nós do MST.

A semente crioula é forte e importante para nosso povo, por isso eu a defendo tanto e busco espalhar meu conhecimento por onde passo. Cultivo e faço trocas com outros companheiros. Essa luta também passou a ser a minha luta. Tornou-se uma paixão. Há pessoas que vêm de Campinas pegar sacas e sacas de sementes aqui conosco. Há outras que vêm do Vale do Ribeira. Fizemos um plantio de milho crioulo, aqui no Irmã Alberta, em parceria com os companheiros do Vale. Muitas sementes crioulas foram para lá.

As reflexões de Paulo Freire, que eu já conhecia desde os tempos de minha atuação no MOVA, assim como as de Josué de Castro (2006) sobre novas matrizes alimentares, entre tantos outros pensadores populares, foram fundamentais para o desenvolvimento do meu trabalho de conclusão nesse curso de especialização. Além de minha orientadora, pude contar com uma coorientadora, que muito me ajudou também, especialmente no que diz respeito à compreensão e fixação de conceitos fundamentais à educação popular e à educação ecológica. Na apresentação e defesa desse meu trabalho, disse a todos que ele não era apenas meu, mas de todos aqueles que haviam participado, direta e indiretamente, do seu desenvolvimento, especialmente as professoras responsáveis pela orientação e coorientação. 


\section{"Não há satisfação maior do que ensinar o que aprendi"}

Chegar a uma escola e lá permanecer por duas horas, à tarde ou à noite, discorrendo e debatendo sobre temas de interesse da comunidade, é muito importante. Debater, por exemplo, sobre reforma agrária, que é um dos principais temas do Movimento, não necessariamente sobre conflitos entre proprietários de terra, mas sobre meio ambiente, é um tema de fundamental importância para uma classe que trabalha a terra e vive desse trabalho. Esse assunto precisa ser debatido sempre, e não apenas algumas vezes. Discorrer sobre produção de alimentos saudáveis, alternativas de vidas, recursos naturais, sobre a água no Planeta e do cuidado com as nascentes, por exemplo, são temas que não se esgotam nunca. Eles deveriam fazer parte de um currículo de formação permanente do trabalhador da terra. Para isso, não precisaríamos de muitos recursos (humanos e financeiros), pois esses temas fazem parte do nosso cotidiano. Há muita gente falando sobre esses temas por aí, mas muito distantes da realidade sobre a qual falam. Trabalham em instituições totalmente deslocadas, ou quase isso, da vida real. Não vivem à beira de um rio poluído, nem precisam dele para sobreviver, como nós. Portanto, temos o conhecimento de causa, como se diz na academia. Onde se vê e se vive a degradação do meio ambiente? Aqui, no Comuna da Terra Irmã Alberta. Somos nós, portanto, os principais interessados nessa causa. É evidente que o conhecimento produzido na academia sobre questões ecológicas é importante, até fundamental, mas isso não basta. Precisamos de políticas públicas de saneamento básico, de uso racional dos recursos naturais e de medidas concretas de proteção ao meio ambiente. Precisamos, também, aprender a aproveitar a água das chuvas e a reutilizar as águas servidas, por exemplo. Nem sempre, entretanto, contamos com os acadêmicos para isso.

Aqui, no Irmã Alberta, já fiz algumas oficinas sobre plantação de uvas e como fazer o manejo depois da colheita. Alguns alunos vieram, tiveram aula prática, mas foi algo passageiro. Seria interessante se houvesse uma agenda permanente, um trabalho sem interrupção sobre essas questões, principalmente as relacionadas à água, que é de extrema importância para todos nós, aqui no acampamento, por ser escassa. A água que abastece o acampamento é capturada de uma fonte natural e é consumida sem tratamento. Ela foi canalizada por todos nós e os custos da canalização foram rateados. Quando o Irmã Alberta deixar de ser um acampamento e passar a ser um assentamento, ou seja, quando a ocupação do terreno for regularizada, vou lutar para termos uma agenda permanente de discussão de todas essas questões. Esse é um dos meus sonhos maiores. A criação de uma escola permanente de EJA é outro sonho.

Para mim, não há satisfação maior do que ensinar o que aprendi, o que eu sei fazer, mesmo sem receber remuneração por esse trabalho. É muito gratificante ouvir de alguém, que foi alfabetizado por você, que pretende dar continuidade aos estudos, porque aprenderam a valorizá-lo e porque se conscientizaram ser o conhecimento fundamental para a vida em sociedade e na natureza. Não se trata de subordinar a natureza aos nossos interesses, mas de aprender a viver nela, porque somos parte dela.

Assim, fui tornando-me uma educadora popular, engajada no movimento organizado dos trabalhadores sem terra. Comprometida, sim, com a luta dos acampados, como eu, aqui, no Comuna da Terra Irmã Alberta, mas, também, com a luta de toda a classe trabalhadora. Sempre atuando no campo da educação, da formação política, social, econômica e cultural da minha gente.

\section{Por uma escola do campo e para o campo}

Diferentemente do que ocorre nos assentamentos, raramente há escolas em acampamentos do MST. Essa é uma das principais razões pelas quais algumas famílias resistem a aderir ao Movimento e a participar das ocupações promovidas por ele. Em nossos trabalhos de base com famílias, elas sempre perguntam sobre os estudos dos filhos, se esses estudos terão continuidade ou não. Essa resistência diminui quando os projetos 
de acampamento são próximos às cidades, porque geralmente há várias escolas no entorno das áreas a serem ocupadas. O Estado é obrigado, por lei, a disponibilizar vagas escolares aos moradores no entorno das escolas públicas. Esse é um sério problema a ser equacionado pelo MST, porque, ainda que haja garantia de vagas escolares para os filhos dos acampados, geralmente essas escolas não são "do campo", nem mesmo "para o campo". Há uma enorme diferença entre esses dois tipos de escola.

Figura 2 - Comuna da Terra "Irmã Alberta"

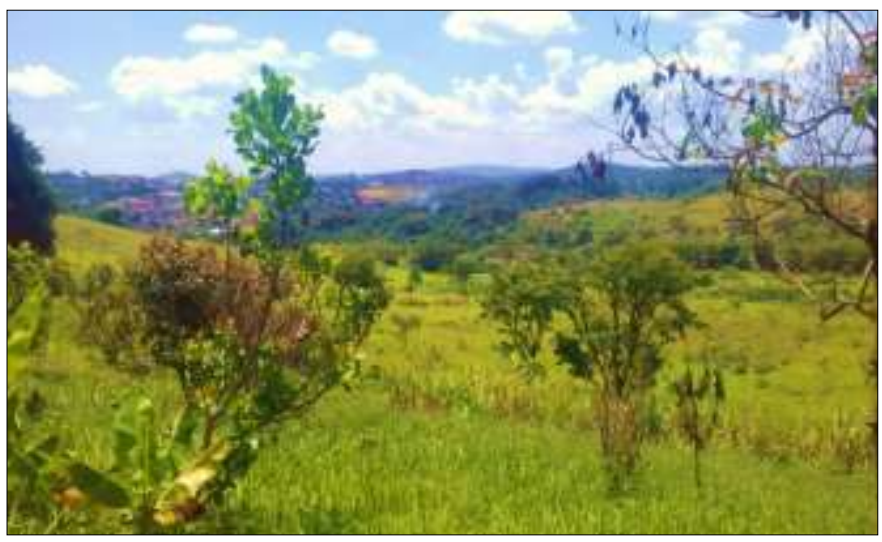

Fonte: Teixeira (2019)

A escola "do campo" deve ser pensada e gerida pelo povo do campo, enquanto a escola "para o campo" é pensada e gerida pelo Poder Público, quase sempre alheio ou muito distante da realidade daqueles que vivem no campo. Por ser o responsável pela montagem de toda a estrutura dessas escolas, acaba também por decidir sobre matrizes e propostas curriculares e métodos de ensino. Não raro, essas escolas fucionam como as urbanas. Acabam por adotar os conteúdos programáticos das escolas urbanas. Seus diretores não têm vínculos com o campo, não são do campo (da roça). Não são, também, filiados ao Movimento e não têm compromisso com a reforma agrária. São escolas que atuam de forma não sincronizada com a realidade do campo.

Quando um professor se propõe a seguir o currículo concebido pela Comissão Pastoral da Terra, sua prática estará articulada ao campo, ao Movimento. Por isso lutamos para que os professores das escolas do campo sejam do próprio acampamento, do assentamento, do Movimento, pois assim trabalharão de acordo com a realidade da criança do campo.

Gosto sempre de ilustrar a compreensão que temos dessa questão, contando uma pequena história sobre uma criança da cidade que foi ao campo e andou a cavalo. Em histórias como essa, é comum haver uma pessoa que cuida do animal, um empregado, e um bonito e bem cuidado rio a embelezar o lugar. A criança que não vive no campo, que apenas vai ao campo a passeio, tende a ver, a representar a vida no campo de forma bastante distorcida, por não pertencer a ele. Já a criança do campo representa o mundo em que vive de modo orgânico, por ser parte dele. Certa vez, fui a uma escola do campo, em Araraquara, onde as crianças diziam saber cuidar da roça, pois acompanhavam os pais na lida diária. Sabiam plantar, colher e preparar o alimento para o próprio consumo.

É por essa vida que lutamos. É uma luta pela educação e fixação do homem no campo.

Quando falo em luta pela educação, é porque me dedico a ela há muito tempo. Educação e educação escolar são práticas sociais interdependentes, mas distintas. Há distinção entre elas, mas também no interior de cada uma delas, como espero ter deixado claro, quando contrapus escola do campo e escola para o campo. Esse mesmo raciocínio se aplica ao exercício de contraposição entre educação pelo trabalho e educação para o trabalho. Não podemos permitir que outros pensem por nós, concebam e imponham dispositivos de 
controle sobre nós. A história ensinada nas escolas é mentirosa. Diferentemente do que é narrado em boa parte dos livros de história, tudo começou com o desrespeito aos povos indígenas, o saque de riquezas para o enriquecimento de outros países, como ocorre até hoje. Somos o "quintal" dos países do primeiro mundo. Quando esses países querem resolver o problema de combustível, por exemplo, plantam cana de açúcar aqui, devastam e contaminam nosso solo, nossas águas, para resolver o problema de combustível deles. Isso é um desrespeito à soberania do país e ao povo deste país.

Passaram-se muitos anos desde o dia em que comecei, ainda jovenzinha, a trabalhar como professora leiga em uma escola rural. A luta por uma educação escolar rural de qualidade, entretanto, mal começou.

\section{Considerações finais}

Compreender a história ${ }^{3}$ como práxis é compreendê-la como um campo de muitas possibilidades. Esse tem sido o pressuposto a animar e a dar sustentação às práticas de pesquisa dos autores deste artigo no campo disciplinar da história da educação, independentemente do momento em que, nele, um e outro começou a atuar. De acordo com esse pressuposto, não há modelos, normas ou leis a reger o curso da história, nem consenso sobre os vários modos de fazer (pesquisa) no interior do campo disciplinar da história. Há apenas práticas singulares de pesquisa, práticas historicamente situadas, portanto. Não são poucos os historiadores de formação e de ofício que reconhecem, explicitam e afirmam tal especificidade, que, diga-se de passagem, não pode ser vista como um "privilégio" do campo disciplinar da história. Dois desses historiadores são bastante conhecidos no Brasil, na área da educação: o inglês, Edward Palmer Thompson, e a brasileira, Déa Ribeiro Fenelon. Em muitos textos de autoria desses dois historiadores, tal compreensão faz-se presente.

Os pontos para reflexão que apresentamos nesta seção poderiam ser perfeitamente ignorados, posto não concorrem para a consecução dos objetivos traçados para este artigo. Entretanto, dado que toda e qualquer prática (ação) humana demanda reflexão (teórica) sobre si mesma, e em atenção aos colegas que trabalham com (ou se interessam por) história oral, com os quais toda e qualquer interlocução é sempre necessária e muito bemvinda - para fins de alargamento da discussão analítica, por exemplo -, optamos por destacar dois pontos para reflexão, intimamente relacionados: o primeiro deles diz respeito à presença da história oral nas práticas de pesquisa em educação, e visa a circunscrever o lugar de inserção da nossa prática - e, consequentemente, também do artigo ora publicado - na historiografia relativa ao tema-problema em tela; e, o segundo, destaca o modo como os autores deste artigo se apropriaram dos produtos de pesquisa e das reflexões filosóficas, teóricas e metodológicas de pesquisadores que balizaram a pesquisa, cujos resultados são parcialmente aqui expostos, a saber: Gramsci (1999; 2001; 2007)), Edward Palmer Thompson (1981; 2002), Jose Larossa Bondìa (2011), José Carlos Sebe Bom Meihy (1991; 2006a; 2006b) e Meihy em coautoria com Fabíola Holanda (2007) e Leandro Seawright (2020); o primeiro faz parte de uma tradição filosófica no âmbito da qual temos construído nossa concepção do mundo, que é pautada pela filosofia da práxis; os dois seguintes estão na base da compreensão que passamos a ter da noção de experiência, e os demais são interlocutores com os quais dividimos a mesma compreensão acerca das possibilidades de produção de saberes no campo disciplinar da história da educação, no diálogo com a história e com a história oral.

\footnotetext{
${ }^{3}$ História como produto das relações que os homens estabelecem entre si e com a natureza ao longo do tempo, e história como prática disciplinar de produção do conhecimento sobre tais relações.
} 


\section{Base teórica da pesquisa realizada}

Começaremos pelo segundo ponto de reflexão, porque entendemos ser necessário explicitar, primeiramente, a base teórica, tanto da pesquisa que realizamos, quanto da leitura crítica que fizemos da amostra da produção historiográfica que trabalha com história oral, na área da educação. Assim procedendo, esperamos poder contribuir para o alargamento da discussão analítica acerca das possibilidades da narração histórica a partir de narrativas orais.

Mari Alves, protagonista da história narrada neste artigo, dificilmente ter-se-ia tornado uma educadora social, tal como se tornou, não fosse o trabalho planejado de vários sujeitos coletivos no seio da sociedade civil (GRAMSCI, 2007). Sujeitos, esses, partícipes de uma concepção do mundo (de uma Weltanschauung) pautada pela filosofia da práxis (GRAMSCI, 1999; 2001). Filosofia, essa, que se caracteriza pela unidade dialética entre reflexão e ação (política), e que visa à negação de práticas sociais (aqui tomadas como expressões sintéticas de práticas econômicas, políticas e culturais) marcadas pela exploração (em todos os sentidos que esse termo possa denotar e conotar). Trata-se de uma filosofia comprometida com uma ação política que não desconsidera a necessidade de uma reforma moral e intelectual da sociedade, com vista à elevação dos grupos sociais dominados à condição histórica de dominantes e dirigentes. Reforma que pode (e deve) ser levada à cabo pela ação política de um partido que se espraia pela sociedade civil e que tem por objetivo formar os quadros políticos necessários à constituição de um novo bloco histórico (GRAMSCI, 2001).

A filosofia da práxis (concepção dialética da história), base de uma leitura crítica da sociedade brasileira na atualidade e das possibilidades de intervenção cultural nessa mesma sociedade, tendo em vista sua transformação política, auxilia-nos a compreender as práticas concretas (historicamente datadas) de organismos políticos comprometidos com tal mudança.

Não seria possível, do nosso ponto de vista, compreender e interpretar a trajetória de vida (e profissional) de Mari Alves, sem levar em consideração tais pressupostos. A pesquisa evidenciou a importância da função intelectual de coletivos (partidos políticos, organizações não-governamentais, instituições escolares e movimentos sociais), bem como a de indivíduos (professores) comprometidos com um processo de reforma intelectual e moral da sociedade, por meio da qual um determinado grupo social pode se tornar dirigente, antes mesmo de se tornar dominante (GRAMSCI, 2001).

Fica evidente, de acordo com essa perspectiva de análise, a importância que se atribui à experiência (vivência) nos processos de formação do ser social, tanto no que diz respeito à educação escolar (formal), propriamente dita, quanto em relação à educação concebida de modo mais global (não-formal), que se dá para além dos muros da escola.

Edward Palmer Thompson (2002), ao discorrer sobre os riscos de uma educação formal não pautada pela experiência, questiona o que a educação formal teria oferecido ao filho do trabalhador, até então? ${ }^{4}$ Ele mesmo responde: - “(...) estilo de vida e hábitos mentais de classe média" (p. 33). Dito isso, apresenta a seguinte tese:

As atitudes em relação à classe social, à cultura popular e à educação tornaram-se "estabelecidas" no período que se seguiu à Revolução Francesa. Durante um século ou mais, a maior parte dos educadores da classe média não conseguia distinguir o trabalho educacional do controle social, e isso impunha com demasiada frequência uma repressão à validade da experiência da vida dos alunos ou sua própria negação, tal como a que se expressava em dialetos incultos ou nas formas culturais tradicionais. O resultado foi que a educação $e$ a

\footnotetext{
${ }^{4} \mathrm{O}$ texto em questão é a transcrição de uma palestra que Thompson proferiu na Universidade de Leeds, em 1968, na quinta conferência anual do Albert Mansbridge Memorial.
} 
experiência herdadas se opunham uma à outra. E os trabalhadores que, por seus próprios esforços, conseguiam penetrar na cultura letrada viam-se imediatamente no mesmo lugar de tensão, onde a educação trazia consigo o perigo da rejeição por parte de seus camaradas e a autodesconfiança. Essa tensão ainda permanece. (THOMPSON, 2002, p. 36; os grifos são nossos).

Ao analisar o enredo do romance Jude the Obscure, de Thomas Hardy ${ }^{5}$, Thompson (2002, p.41), não encontra, nesse romance, uma rejeição da cultura letrada em favor da experiência, mas a afirmação da "dialética necessária entre a educação e a experiência". E indaga: - "Até que ponto as oportunidades educacionais mais amplas diminuíram a distância fria", historicamente forjada "entre a cultura letrada e a cultura das classes populares"? Para ele,

Não há correlação automática entre o 'sentimento real e a razão justa' ${ }^{9} \mathrm{e}$ as conquistas educacionais, mas as pressões de nossa época [fins dos anos de 1960] estão nos levando a confundir as duas coisas - e os professores universitários, que nem sempre se destacam por sua humildade, estão frequentemente prontos a concordar com essa confusão. É sempre difícil conseguir o equilíbrio entre o rigor intelectual e o respeito pela experiência, mas hoje em dia esse desequilíbrio está seriamente prejudicado. (THOMPSON, 2002, p. 46).

A experiência singular de Mari Alves é uma evidência histórica de que esse "equilíbrio entre o rigor intelectual e o respeito pela experiência" a que Thompson se refere continua a ser uma utopia no Brasil atual, apesar das pouquíssimas, porém honrosas, exceções - as práticas político-pedagógicas de alguns professores que fizeram parte da história de vida de Mari Alves, por exemplo.

Mais recentemente, Jorge Larossa Bondìa, pedagogo de formação e professor de filosofia da educação na Universidade de Barcelona, agregou outros elementos à noção de experiência que buscamos em Edward Palmer Thompson. Fortemente ancorado nas reflexões de Walter Benjamin, Larossa Bondìa afirma que, experiência é "isso que me passa" (2011, p. 5, grifo do autor). Esse entendimento contempla, segundo o autor, o princípio de alteridade ("o passar de algo que não sou eu" - na definição, representado pelo pronome demonstrativo "isso"), o princípio de subjetividade, de reflexibilidade, de transformação ("o lugar da experiência sou eu" - na definição, representado pelo pronome pessoal "me"), o princípio de

\footnotetext{
5 Thomas Hardy, romancista, poeta e historiador, nasceu em Higher Bockhampton, província de Dorset, Inglaterra, no dia 02 de junho de 1840, e faleceu em Londres, no dia 11 de janeiro de 1928. "Judas, o obscuro", foi publicado em capítulos na revista Harper's, em 1895, e, em edição completa, em 1896. O romance, sempre lembrado por estudiosos ingleses, como Raymond Williams e Edward Palmer Thompson, retrata a vida de um jovem e pobre pedreiro, Judas Fawley, em uma Inglaterra marcada pela decadência (última década do século XIX) dos valores apregoados no apogeu da era vitoriana. Judas sonhava em estudar em uma universidade. Tentou ingressar em uma delas (Christminster), mas foi recusado. O mais perto que, dela, chegou, foi como pedreiro. Almejava ter acesso aos saberes e ao conhecimento que a universidade produzia, mas distribuía de forma extremamente desigual. Mesmo sendo preterido, nutriu, até a morte, o sonho de um dia ser aceito por ela.

${ }^{6}$ Referência ao poema The Prelude, de William Wordsworth (07/04/1770 - 23/04/1850), considerado um dos maiores poetas românticos da Inglaterra. O trecho desse poema, citado por Thompson (2002, p. 21) é o seguinte: "Quando comecei a inquirir, / A observar os que encontrava e a lhes fazer perguntas, e manter / Conversas familiares com eles, as estradas solitárias / Tornaram-se escolas para mim, nas quais eu lia diariamente / Com o maior prazer as paixões da humanidade, / Ali eu via nas profundezas das almas humanas, / Almas que parecem não ter nenhuma profundidade / A olhos comuns. E agora, convencido de todo o coração / De que aquilo a que nós sozinhos damos / O nome de educação tão pouco tem a ver / Com o sentimento real e a consciência justa... [(...) versão de 1805 de The Prelude, org. E. de Selincourt, Oxford University Press]”.
} 
passagem ("uma saída de si para outra coisa" - na definição, representado pelo verbo "passar"), e, por fim, o princípio de paixão, assim definido:

Se a experiência é "isso que me passa", o sujeito da experiência é como um território de passagem, como uma superfície de sensibilidade em que algo passa e que "isso que me passa", ao passar por mim ou em mim, deixa um vestígio, uma marca, um rastro, uma ferida. Daí que o sujeito da experiência não seja, em princípio, um sujeito ativo, um agente de sua própria experiência, mas um sujeito paciente, passional. Ou, dito de outra maneira, a experiência não se faz, mas se padece. (LAROSSA BONDİA, 2011, p. 8, grifo e destaques do autor).

Por essas razões, a experiência seria sempre singular (princípio de singularidade), irrepetível (princípio da irrepetibilidade) e plural de singular (princípio de pluralidade) (Larossa Bondìa, 2011, p.15-17).

Essa reflexão de Larossa Bondìa reforça a avaliação de Thompson sobre o desequilíbrio entre "sentimento real e razão justa" e as "conquistas educacionais" que ele identifica na sociedade inglesa dos anos de 1960. Entendemos que tal desequilíbrio também se faz presente na sociedade brasileira de hoje. Certo é que as classes populares que constituem a sociedade brasileira têm sido de certa forma contempladas pelas políticas públicas de escolarização, postas em prática no país desde meados do século passado. Certo é que essas mesmas classes populares, não na sua totalidade, evidentemente, têm tido acesso, bem ou mal, à cultura letrada. Entretanto, isso só não basta. Não se trata de "abrir as portas" do ensino médio e universitário às classes populares, como se tal medida fosse condição necessária e suficiente ao estreitamento da distância entre um e outro segmento social. Condição necessária, sim, mas não suficiente. Esse segmento social tem ingressado no sistema de ensino, mas continua a ser ignorado por aqueles que detêm o controle sobre ele: políticos, dirigentes e professores - não todos, felizmente. É como se fossem "invisíveis", poderíamos dizer, traçando um paralelo entre essa nossa percepção e a do narrador da experiência de Judas Fawley, personagem do livro de Tomas Hardy, Jude the Obscure, quando ele se refere à maneira como Judas foi "visto" pelos estudantes da Universidade de Christminster, quando lá trabalhava como pedreiro ${ }^{7}$. Ou, então retomando a interpretação de Thompson (2002, p. 39), já referida neste artigo -, uma evidência da incapacidade do sistema de ensino em não conseguir "distinguir o trabalho educacional do controle social", impondo "uma repressão à validade da experiência da vida dos alunos ou sua própria negação". Passados mais de duzentos anos desde a publicação de The Prelude, e mais de cem, desde a publicação de Jude the Obscure, o desequilíbrio entre "sentimento real e razão justa" e as "conquistas educacionais" continua a se fazer presente no Brasil. A tese defendida por Mari Alves sobre a necessidade de uma escola do campo e para o campo pode ser tomada como expressão desse desequilíbrio a que Thompson se refere. E, a transcriação analítica apresentada neste artigo pode ser tomada como aquilo que "passou", que deixou marcas nos "territórios de passagem" daqueles que viveram direta ou indiretamente a experiência a que Larossa Bondìa se refere, ou seja, os autores deste artigo.

As reflexões de Antonio Gramsci, Edward Palmer Thompson e Jorge Larossa Bondìa, acima destacadas, possibilitam compreender os nexos (a racionalidade) das escolhas metodológicas dos autores deste artigo no campo da história oral. A identidade que construímos com as abordagens de José Carlos Sebe Bom Meihy e as de alguns dos componentes do grupo

\footnotetext{
7 "Ele era um jovem operário de blusa branca e pó de pedra nas dobras das roupas; e, ao passar por ele, eles nem mesmo o viam, ou ouviam, mas, ao contrário, viam através dele, como se ele fosse uma vidraça, quando olhavam para seus familiares mais adiante" (HARDY apud THOMPSON, 2002, p. 39).
} 
de pesquisa que ele coordenou por vários anos, como Fabíola Holanda e Leandro Seawright, deveu-se, basicamente, a tais reflexões. Assim, passamos a considerar a história oral como "prática transformadora da realidade" (MEIHY, 2006b), uma vez que a relação entre entrevistado (colaborador) e entrevistador (pesquisador/oralista) é sempre mediada pela noção de experiência (THOMPSON, 2002; LAROSSA BONDİA, 2011). Subjacente a essa compreensão, está o princípio, segundo o qual, os sujeitos são totalidades significativas forjadas no bojo das relações que estabelecem entre si e com a natureza. De acordo com essa concepção, entrevistado e entrevistador deixam-se moldar em situações de entrevista. Nisso residiria, do nosso ponto de vista, a marca distintiva da história oral como disciplina produtora de um saber distinto daquele produzido em outros campos disciplinares do conhecimento.

"Sabedoria" como forma de conhecimento diz respeito à valorização da experiência humana, de maneira a elevar o sentido moral da vivência individual ou coletiva. Como maneira superior de reconhecimento de vivências humanas, saber tem mesmo mais sentido do que o simples registro, e as histórias ganham sentido social exatamente por isso. (MEIHY; HOLANDA, 2007, p. 74).

Um dos pontos altos do reconhecimento da história oral como saber reside na possibilidade de constituí-la como uma categoria à parte do conhecimento científico que, mediante ela, passa a ser sempre diagnóstico. (MEIHY; HOLANDA, 2007, p. 75.

Há que se destacar, por fim, que as entrevistas realizadas com Mari Alves, base da narrativa apresentada neste artigo, não foram por nós, historiadores da educação que trabalham com narrativas orais, tomadas como prática discursiva desprovida de contradições, apenas por terem sido narradas por um representante de um segmento social historicamente explorado por forças sociais que dominam e dirigem uma sociedade como a nossa, que é de base capitalista, e que integra um sistema intrincado de relações internacionais de dependência. As narrativas orais de Mari Alves apresentam, ao mesmo tempo, traços de uma visão do mundo que se fez e ainda se faz hegemônica em nossa sociedade, e que tende a naturalizar o que é expressão de práticas econômicas, sociais, políticas e culturais concretas, portanto, historicamente datadas, bem como traços que negam essa mesma visão do mundo.

Em síntese, podemos afirmar que Gramsci, Thompson, Larossa Bondìa, Meihy, Holanda e Seawright, em seus respectivos tempos históricos e campos disciplinares de atuação, partilham de uma tradição filosófica questionadora da utilização de paradigmas tradicionais no processo de produção do conhecimento. $\mathrm{Na}$ área da educação, também encontramos pesquisadores com esse mesmo perfil. Guacira Lopes Louro, por exemplo, foi uma das primeiras pesquisadoras a questionar, no Brasil, o modo tradicional de se pesquisar no campo disciplinar da história da educação.

\section{A história oral na pesquisa em educação}

Em um dos primeiros artigos que publicou, Guacira Lopes Louro apresenta a seguinte avaliação da produção historiográfica sobre a educação no país:

A tradicional pesquisa em história da educação está por aí registrada, falando das iniciativas de grandes homens, "evocando" instituições, campanhas educativas, ligas de alfabetização, leis, eventos, e datas, muitas datas. Mas os sujeitos concretos desta história ficaram 
escondidos: O que se sabe das professoras e professores unidocentes, da forma como organizavam suas aulas e atendiam seus alunos? Que relações eles estabeleciam com as famílias e as comunidades? O que representava a escola para os pequenos filhos dos imigrantes no interior do Brasil? O que se ensinava e como? O que pais e mães consideravam importante na educação dos meninos e meninas dos anos vinte, ou trinta, no Rio de Janeiro, no interior de Minas, ou na Bahia? Como era um colégio interno da elite paulistana na década de quarenta? O que se fazia para burlar a autoridade e o controle num internato? O que a cidade grande ensinou para o migrante nordestino? Ela aproveitou seus outros saberes? O que era uma dona-de-casa prendada, no entendimento da gente da campanha rio-grandense? Como as professoras conciliam suas tarefas profissionais e familiares? Como a greve é vivida pelas professoras, professores e estudantes? (LOURO, 1990a, p. 29).

Em fins da década dos anos oitenta do século passado, Guacira afirmava haver, ainda, muitas outras questões a formular, e estar convencida de que "no encaminhamento de algumas problemáticas", a história oral poderia ser "um ponto de apoio fecundo, a lançar luz sobre sujeitos e temas ensombrecidos" (LOURO, 1990a, p. 29). Passados mais de trinta anos, a historiografia da educação no Brasil tem se voltado para os "excluídos" da história e, no âmbito dessa produção, encontram-se muitos trabalhos de pesquisa que recorrem a narrativas orais.

Uma rápida busca na Web possibilitou aferir, ainda que de maneira bastante precária e provisória $^{8}$, como a história oral vem sendo atualmente utilizada na área da educação ${ }^{9}$. Tal busca possibilitou a identificação de pelo menos dois blocos de trabalhos de pesquisa que recorrem à história oral - principalmente teses de doutorado e dissertações de mestrado, publicadas em formato de artigo, na imprensa especializada em Educação, ou na forma de trabalho, apresentado em eventos realizados na área da Educação.

O primeiro desses dois blocos reúne trabalhos que privilegiam uma multiplicidade de temas e questões, sobressaindo-se, entretanto, os que elegem, como objeto de análise, a formação docente, tanto em termos genéricos, como no que diz respeito à formação profissional de docentes que atuam em campos disciplinares distintos, como História, Matemática, Educação Física, Educação Especial e Ciência, por exemplo; trabalhos que tendem a considerar a formação profissional como um processo balizado, grosso modo, pela formação inicial (escolar) e pela formação em serviço (formação continuada); alguns deles, entretanto, prendem-se à análise de apenas um desses dois marcos temporais, desconsiderando, assim, o percurso formativo como um todo.

O segundo bloco de trabalhos reúne estudos sobre a pertinência (limites e possibilidades) da história oral para a história da educação; assim procedendo, levantam a possibilidade de se pôr em discussão questões teóricas e metodológicas respeitantes aos modos

\footnotetext{
${ }^{8}$ A lógica de rastreamento do que é publicado na Web é ainda pouco conhecida. Não se sabe com clareza, por exemplo, quais critérios são utilizados por programas rastreadores, como Google, Safari e outros, na busca das informações solicitadas.

${ }^{9}$ Para a realização dessa busca, valemo-nos do seguinte descritor: história oral na pesquisa em educação no Brasil. Apesar das mais de 25 milhões de ocorrências localizadas pelo rastreador, selecionamos, para leitura e análise, apenas as referências que correspondiam exatamente ao descritor utilizado. Tais cuidados fizeram-se necessários, pois o resultado da busca incluía referências que não guardavam relação ou se relacionavam de maneira muito indireta com o tema de interesse da pesquisa. Evidentemente, avançamos até onde foi possível na leitura das páginas que trazem a identificação e o endereço eletrônico dos trabalhos localizados, selecionando um número que consideramos bastante razoável - cerca de trinta trabalhos - para o que desejávamos. Essa amostra constituiu o corpus documental principal da análise, cujos resultados são aqui apresentados.
} 
recorrentes de fazer pesquisa em educação, desde a publicação dos primeiros resultados de pesquisas realizadas na área, que fizeram uso da história oral. ${ }^{10}$

Em ambos os blocos, evidenciam-se as concepções que os pesquisadores em questão têm da história oral (mas não apenas dela), ora apresentada e trabalhada como fonte complementar aos demais materiais da pesquisa histórica (preenchimento de "lacunas"), ora concebida como instrumento ou ferramenta de pesquisa, ou seja, como um conjunto de procedimentos (técnicas) voltados à produção de fontes documentais escritas a partir de narrativas orais obtidas por meio de entrevistas (estruturadas, semiestruturadas ou abertas). Essa é a regra, que explicita possibilidades de pesquisa distintas daquela, por nós, considerada.

Um único trabalho (HAAS, 2012) destaca-se do conjunto de trabalhos analisados, por focalizar sujeitos historicamente ignorados na produção do conhecimento sobre a história da educação no Brasil, nos termos apresentados por Louro (1990a), e por propor um itinerário de pesquisa com história oral pautado por uma visão do mundo que reconhece e admite a presença ativa da subjetividade no processo de produção do conhecimento.

Haas (2012) expressa uma compreensão acerca da presença da história oral, na pesquisa em educação, que muito se aproxima do entendimento que caracteriza, a nosso juízo, as práticas de pesquisa do Núcleo de Estudos em História Oral da Universidade de São Paulo: a possibilidade de a história oral ser pensada e trabalhada, não como prática instrumental que visa à produção de fontes escritas a partir de narrativas orais, mas como disciplina e metodologia com estatuto próprio, que amplia a compreensão de fonte oral, opera com conceitos de verdade e realidade ancorados em paradigmas que se contrapõem aos tradicionais, os quais consideram a subjetividade uma presença incômoda, não desejada, no processo de produção do conhecimento, pois tal presença estaria a interferir, negativamente, na apreensão "objetiva" do real e, portanto, a dificultar, ou até mesmo a impedir, o conhecimento da "realidade", produzindo-se, assim, um conhecimento "não-verdadeiro". Na história oral, tal como se apresenta em Haas (2012) e nos estudos e textos vinculados ao Núcleo de Estudos em História Oral da Universidade de São Paulo - bem como neste nosso artigo -, o resultado final do trabalho com entrevistas não corresponderá, de forma "objetiva" e "reflexiva"11, às narrativas dos entrevistados, mas à narrativa do pesquisador (oralista), que, em tese, comunicará a compreensão sintética que ele teve dos assuntos tratados na dinâmica da pesquisa. Essa síntese pode ser interpretada como expressão de uma relação dinâmica, portanto de interação (e de identidade, em muitos casos), entre entrevistado e entrevistador - ou entre colaborador e oralista, como entendem Meihy (2006a), Meihy e Holanda (2007) e Meihy e Seawright (2020)

${ }^{10}$ Vale registrar, aqui, alguns desses trabalhos, que podemos considerar "pioneiros". São dignos de nota, por exemplo, dois artigos publicados por Guacira Lopes Louro: um sobre a fertilidade da história oral para as escritas da história da educação daqueles que foram excluídos da historiografia tradicional (1990a), e outro sobre a educação da mulher imigrante italiana no Rio Grande do Sul, que se deu fundamentalmente no trabalho (1990b). E, ainda, os trabalhos apresentados no II Encontro Nacional de História Oral: História Oral e Multidisciplinaridade, realizado em abril de 1994, na cidade do Rio de Janeiro, sob a coordenação geral do Centro de Pesquisa e Documentação de História Contemporânea do Brasil da Fundação Getúlio Vargas, de autoria de: 1) Zeila de Brito Fabri Demartini, sobre relatos orais e educação (trajetórias profissionais de homens e mulheres no magistério primário), realizados no Centro de Estudos Rurais e Urbanos, sociedade sem fins lucrativos dedicada à pesquisa em ciências sociais, vinculado ao Departamento de Ciências Sociais da Faculdade de Filosofia, Letras e Ciências Humanas da Universidade de São Paulo; 2) Maria Cristina Guido, sobre gênero (educação feminina católica), realizados no Museu da República, vinculado à Fundação Nacional Pró-Memória, no Rio de Janeiro; 3) Elza Nadai (USP), Ricardo Ribeiro (Unesp), Sonia Maria Leite Nikitiuk (UFF) e Diva do Couto G. Miniz (UnB), sobre história e memória de professores (a institucionalização da escola pública no Brasil e a organização da profissão docente); 4) Irene Maria F. Barbosa (Unesp), sobre questões metodológicas decorrentes da utilização de diferentes fontes de pesquisa (a escola como estratégia de superação de desigualdades: reconstrução de trajetórias escolares de sujeitos vítimas de preconceito de raça). Cf. Ferreira (1994), que reproduz os resumos dos trabalhos apresentados nesse II Encontro Nacional de História Oral. É numericamente significativa, entretanto, a produção de trabalhos científicos, na área da educação, que fazem uso da história oral.

${ }^{11}$ Sobre as possibilidades epistemológicas em questão, consultar, entre outros, Thompson (1981, especialmente p. 9-62) e Schaff (1978, especialmente, p. 65-98). 
-, ambos tomados como sujeitos simultaneamente ativos e receptivos de uma relação cognitiva historicamente datada. Por essa razão, assumimos as narrativas, tanto as dos colaboradores quanto as dos oralistas, como objetivas e verdadeiras, porque consensuais e compartilhadas.

Em síntese, poder-se-ia dizer, reportando-se à epígrafe que abre este artigo, que o esforço dos seus autores consistiu em promover o encontro da "memória sentida" com a "memória do sentido", que se materializou por meio de um projeto de pesquisa, no âmbito do qual a memória dos autores (pesquisadores/oralistas) procurou acolher as lembranças da entrevistada (colaboradora), Mari Alves. Esse processo de acolhimento ensejou, por sua vez, a constatação de como os autores (pesquisadores/oralistas) se deixaram impactar por "intersubjetividades em contato com o mesmo e o diverso", e, ainda, a evidenciação de como a atuação da entrevistada (colaboradora) "recriou a dinâmica de compreensões" de todos os envolvidos no projeto (MEIHY; SEAWRIGHT, 2020, p. 162).

\section{Referências}

CASTRO, Josué. Geografia da Fome: o dilema brasileiro. Pão ou Aço. Rio de Janeiro: Civilização Brasileira, 2006.

FERREIRA, Marieta de Moraes (Org.). História Oral e Multidisciplinaridade. Rio de Janeiro: Diadorim, 1994.

GRAMSCI, Antonio. Cadernos do Cárcere, volume 1 (Introdução ao estudo da filosofia. A filosofia de Benedetto Croce.). Rio de Janeiro: Civilização Brasileira, 1999.

GRAMSCI, Antonio. Cadernos do Cárcere, volume 2 (Os intelectuais. O princípio educativo. Jornalismo.). 2. ed. Rio de Janeiro: Civilização Brasileira, 2001.

GRAMSCI, Antonio. Cadernos do Cárcere, volume 3 (Maquiavel. Notas sobre o estado e a política.). 3. ed. Rio de Janeiro: Civilização Brasileira, 2007.

HAAS, Clarissa. A história oral como itinerário de pesquisa na educação especial: construindo narrativas de "aceitação do outro como legítimo outro". In: IX ANPEd Sul: Seminário de Pesquisa em Educação na Região Sul. Caxias do Sul, RS, 2012. Disponível em: http://www.ucs.br/etc/conferencias/index.php/anpedsul/9anpedsul/paper/viewFile/312/683.

Acesso em: 17 abr. 2021.

LAROSSA BONDİA, Jorge. Experiência e Auteridade em Educação. Revista Reflexão e Ação, Santa Cruz do Sul, vol.19, n.2, p.4-27, jul./dez/ 2011. DOI: https://doi.org/10.17058/rea.v19i2.2444

LOURO, Guacira Lopes. A História (Oral) da Educação: algumas reflexões. Em Aberto, Brasília, DF, v. 9, n. 47, jul./set. 1990a, p. 20-29.

LOURO, Guacira Lopes. Lembranças de Velhas Colonas Italianas: trabalho, família, educação. Educação \& Realidade, Porto Alegre, v. 15, n. 2, jul./dez. 1990b, p. 33-43. 
MEIHY, José Carlos Sebe Bom. Augusto \& Lea: um caso de (des)amor em tempos modernos. São Paulo: Contexto, 2006a.

MEIHY, José Carlos Sebe Bom. Canto de Morte Kaiowa: história oral de vida. São Paulo: Loyola, 1991.

MEIHY, José Carlos Sebe Bom. Os novos rumos da história oral: o caso brasileiro. Revista de História, São Paulo, n.155, 2 sem./2006b, p.191-204. DOI: https://doi.org/10.11606/issn.23169141.v0i155p191-203

MEIHY, José Carlos Sebe Bom; HOLANDA, Fabíola. História Oral: como fazer, como pensar. São Paulo: Contexto, 2007.

MEIHY, José Carlos Sebe Bom; SEAWRIGHT, Leandro. Memórias e Narrativas: história oral aplicada. São Paulo: Contexto, 2020.

SCHAFF, Adam. História e Verdade. São Paulo: Martins Fontes, 1978.

SILVA, Maria Alves. A Luta por Terra e Educação no Acampamento da Comuna da Terra Irmã Alberta. São Carlos, SP: Universidade Federal de São Carlos (Trabalho de Conclusão de Curso em Pedagogia da Terra), 2011.

SILVA, Maria Alves. Práticas Sociais e Processos Educativos de Conservação e Uso de Sementes Nativas e Crioulas na Comuna da Terra Irmã Alberta. São Paulo: Faculdade de Educação da Universidade de São Paulo (Trabalho de Conclusão de Curso Especialização/Residência Agrária: Educação do Campo e Agroecologia), 2015.

TEIXEIRA, Paulo Rogério de Oliveira. A Educação Escolar no Movimento dos Trabalhadores sem Terra, na Visão dos Acampados. Santos, SP: Programa de Pós-Graduação Stricto Sensu em Educação da Universidade Católica de Santos (Dissertação de Mestrado), 2019.

THOMPSON, Edward Palmer. A Miséria da Teoria ou Um Planetário de Erros: uma crítica ao pensamento de Althusser. Rio de Janeiro: Zahar, 1981.

THOMPSON, Edward Palmer. Educação e Experiência. In: Os Românticos. A Inglaterra na Era Revolucionária. Rio de Janeiro: Civilização Brasileira, 2002, p. 11-47. 